\title{
Changing scenario during COVID-19 pandemic
}

\author{
Gehanath Baral \\ Editor-In-Chief, Nep J Obstet Gynaecol
}

Received: June 5, 2020

Accepted: June 8, 2020

\begin{abstract}
Regular activities, management, behavior, livelihood and regulations have been altered and customized during pandemic to cope with the newly appeared challenges. All steps of life have been affected unexpectedly. The epidemiological, political, clinical and psychosocial scenarios have been changing as the time passes; thus the initial guidelines and regulation are not enough to combat crisis over time.
\end{abstract}

Keywords: covid, crisis, guideline, pandemic, testing

Citation : Baral G. Changing scenario during COVID-19 pandemic. Nep J Obstet Gynecol. 2020;15(30):7-8. DOI: 10.3126/njog. v15i1.29332

\section{INTRODUCTION}

Pandemic and other natural disasters date back to centuries time and again. That could be plague, cholera, Earthquake, Tsunami, draught, fire or even the man made ones like world war, cold war and conflicts. ${ }^{1,2}$ Current pandemic declared on $12^{\text {th }}$ March 2020 for COVID-19 caused by SARS$\mathrm{CoV} 2 .^{3}$ Initial clinical guidelines were released to address the information available till that date and evolving course of disease prompted to alter the clinical practice. Same applies to the regulation and policy from governing bodies.

\section{CHALLENGES}

Initial clinical management started with treating pneumonia and ARDS; and then to endothelial injury and hyper coagulation. ${ }^{4,5}$ Likewise, empirical drug treatment and supportive or health promotive measures evolved. Now the stage has come to wait for herd immunity ${ }^{6}$ and vaccine development. ${ }^{7}$ Screening and testing initially advocated for contact, travel and flue symptom like fever. Later on as the asymptomatic cases were in bulk then the testing has become imperative to all cases undergoing surgery then to all cases that require hospital admission. Elderly and co-morbid conditions were focused first from the initial epidemiologic characteristics but later included younger age group too. ${ }^{8}$ The stage has come to universal screening, testing and precaution currently. Ill-defined natural history and viral mutations are the challenges in developing effective microbial intervention. ${ }^{9}$

There are several health related scenario couplets that require scientific strategy and real time judgment like in contact and community transmission, re-infection and passage of non-infectious viral fragment, ${ }^{10}$ asymptomatic carrier and window period, testing antigen and antibody, ${ }^{11}$ preventing and treating infection, treating disease and promoting health, quarantine and isolation, disinfection and sealing, and security and right.

Non-health couplets like work and pay, product and value, necessaries and supplies, society and economy, service and regulation, conscience and ignorance, dynamism and inertia, full-fledged and limited, and harmony and conflict are adversely affecting livelihood. ${ }^{12}$

\section{INTERVENTION}

General measures in preventing transmission by distancing, hand hygiene and sanitization, protective barrier, public education, adequate supplies and protecting service providers and service delivery

\section{CORRESPONDENCE}

Prof Dr Gehanath Baral

Editor-In-Chief, Nepal Journal of Obstetrics and Gynaecology

Email: njogeditor@gmail.com; gehanath@gmail.com 